Filo. y Lingüí. 4(1): 13-16, 1978

\title{
SEMPRONIA EN LA CONJURACION DE CATILINA
}

Francisco Vindas Ch.

Entre los retratos que Salustio nos presenta en and aînas, merece un lugar destacado el que nos ofre= EI el capitulo XXV DE CONIURATIONE Z TILAE por el encanto particular de SemproInIII- Al cual nace del contraste de características: $=1=1$ inteligencia, cultura, lujuria, criminalidad, 7nernersión. A través de las tintas claro-oscuras del inistruciador latino emerge un típico cuadro de inururalidad femenina que nos hace recordar a Wwatumeres de la alta sociedad, cuyos rasgos viven en la poesía inmortal de Catulo: naturalmente nan plense de inmediato en Clodia.

En Sempronia no resalta solamente la belleza; zumo sucede en el caso de Clodia, sino también el manctivo de una instrucción superior. El medallón winustiano es de tal manera representativo, que Bo- zulieribus, no da su nombre. Entre los histotulitores posteriores a Salustio, Apiano se refiere a Sempronia.

De esta mujer y de su participación en la conunación de Catilina solamente Salustio nos dejó recuerdos. Cicerón, que se complace también en minimas evocaciones, se refiere a los acontecimienInex, en los cuales se presume haya participado pero and menciona su nombre en las Cat. III, 6, 14. De lins historiadores posteriores, tanto Apiano como Casio Dión nos han llegado con lagunas, cabalmente en la página en la cual, probablemente haIrismos podido tener noticia de ella; mientras FloID (II, 12,1) nos rinde detalles muy minuciosos.

Entorno a la figura de Sempronía surgieron muchas hipótesis. Ante todo no queda claro el mo tiv y cabalmente en aquel punto de su historia; en segundo lugar es importante definir a qué familia pertenecía la noble dama.

Respecto al primer punto se ha buscado de explicar esta intercalación con motivos de orden externo. Schwartz, por ejemplo, piensa que Salustio ha querido adrede castigar en Sempronia la mathe del cesaricida Décimo Bruto Albino. Otros, a su vez, han pensado en motivos de índole artística; otros, como Bolaffi, (1) piensan que Salustio obedece a un fin político, con la intención de castigar la clase aristocrática. Estos motivos genéricos, sin embargo no aparecen del todo convincentes, no obstante ser perfectamente verosímiles. Se ha pensado, con todo, que esta noble dama ha desempeñado un papel de notable importancia en la conjuración, de tal magnitud que Salustio la destacó de todas las otras damas de las cuales él mismo habla, sin nombrarlas, en el capítulo XXIV. Sería también de este modo esclarecido el porqué de la inserción de la semblanza en este punto, es decir, al inicio del segundo momento de la conjuración.

Trataré de demostrar que esta misteriosa figura de mujer es algo más que una simple comparación, insertada por motivos no políticos, tomando el punto de partida del segundo, valga decir de algunas conjeturas que Ciaceri propone sobre la familia a la cual Sempronia perteneció. (2)

Ciaceri aceptaba, en un primer paso, además de la hipótesis de Schwartz, quien demostró que Sempronia fue la madre de Décimo Bruto Albino, el cesaricida, aquella otra de Münzer, para quien la acusa que Salustio le enrostra de haber participado en la conjuración, hallaría razón en el pertenecer ella a la familia de los Gracos, aún más, en ser hija de Cayo Graco, tribuno del año 123-122. En este punto Ciaceri advierte la incoherencia de Salustio en castigar a la mujer que pertenecía no a las familias oligárquicas y silanas de Roma, sino al de los Gracos, y probablemente ésta era hija del Cayo Graco, que con sobrada razón, fue considerado como creador, fundador del partido democrático y precursor de César, de quien el mismo historiador no por algo es ferviente admirador. Este pensamiento expresado, con un tanto de reserva, en el estudio sobre Cicerón, llega a ser después principal argumento contrario a la.hipótesis de Münzer en el antes mencionado estudio sobre Sempronia: parece inconcebible, en realidad, que Salustio pensase en fustigar, llenando de oprobio, el nombre de la 
hija de aquél que Salustio no diversamente de César, debía considerar como el precursor del partido democrático. Ciaceri debe por esto encontrar entre todas las Sempronias de esa época, una con la cual poderla identificar $\mathrm{y}$, no hallándola, buscarse otra, quien pudiese satisfacer las exigencias históricas, si no faltase los elementos de prueba de la existencia de tal personaje; y a esto llega Ciaceri llevado de algunas consideraciones, no todas de acuerdo con la realidad y sobre todo del creer que si se hubiese tratado de una hija del famoso tribuno, no habría permanecido callado, el gran orador, de dar un golpe al partido contrario, ya fuera cuando hablaba de la conjuración, o bien en otros momentos de su vida.

Ahora bien, Cicerón tuvo muchísimàs ocasiones de criticar a los Gracos a través de sus cuatro Catilinarias, pero jamás empleó frases que pudieran ser tomadas por verdaderos y auténticos ataques contra su recuerdo o contra sus familias. "Ti. Gracchum, mediocriter labefactantem statum reipublicae" (Cat. I,3); "interfectus est propter quasdam seditionum suspiciones $C$. Gracchus, clarissimo patre, avo, maioribus" $(\mathrm{I}, 4)$; "summi et clarissimi viri/ . . . Gracchorum" (I,29); "Ti. Gracchus, quod agrarios concitare conatus est" (IV,4).

Cicerón, en tiempo de su consulado, más que odiar a los Gracos demostraba hacia ellos por lo menos una cierta estimación; tal vez porque en aquel momento especial, a propósito de las leyes agrarias, tenía todo el interés de poner en buen lugar a los Gracos, ya que bien sabía que impidiendo la aprobación de la rogatio Servilia, combatía a favor de las tesis tanto de Pompeyo como del senado, en nombre de las ideas de los Gracos, en contra de las astutas y engañosas propuestas del partido de César y Graco. Y como confirmación de lo dicho anteriormente, basta recordar el año 60, cuando la rogatio. Servilia se cambió en lex Iulia, propuesta por el mismo César. Por lo tanto aparece manifiesta disidencia entre las ideas de los Gracos y que Salustio había tomado como suyas al ingresar en el partido de César.

Faltando, pues, este argumento contrario a la tesis de Münzer, se desbarata todo lo propuesto por Ciaceri; Sempronia aparece así como la hija de Cayo Graco, madre de Décimo Bruto Albino, cónsul en el 77, según las hipótesis de Schwartz y de Münzer. Pero las razones adoptadas por Ciaceri para demostrar la útil validez de los argumentos son por otra parte muy poco fundados en cuanto que, si estos parentescos pueden llegar a crear una atmósfera de simpatía o de antipatía y hasta echar luz sobre muchas relaciones políticas en confrontación con Sempronia, no bastan para ayudar la bien determinada postura de nuestras fuentes históricas; y por lo tanto será tal vez necesario, buscar, como ya antes se ha hecho alusión, otra posible y diversa interpretación por medio de las noticias de que podemos echar mano.

De la narración de Salustio sabemos que la conjuración de Catilina tuvo dos momentos: el primero que podría definirse el más estrechamente oligárquico, en el cual los conjurados eran de preferencia senadores y caballeros, refiérome a los conjurados de las calendas de junio (Cat. XVII); el otro, en vez, más demagógico, en el cual, para ampliar la conjuración, Catilina no desdeñó admitir, como secuaces de sus proyectos, hombres de cualquier condición social y también algunas mujeres, con tal de lograr cualquier benefecio; y; son éstos los conjurados de agosto (Cat. XXIV). Vemos, así, qué diversos son los integrantes de la conjuración; observamos que en el primer grupo Curio se hace delator por medio de Fulvia (Cat. XXIII); y la narración que nos hace Salustio es bien verosímil. Aparecido el espionaje casualmente, al propagarse la noticia en el ambiente aristocrático, ésta llega hasta oídos de Cicerón, quien antes víctimas de la envidia senatorial, llega a ser ídolo y protector de los más convencidos conservadores. Confirmación del espionaje realizado por Fulvia está el testimonio de todos los historiados, empezando por Salustio. Cicerón se da por enterado del asunto cuando se realiza la visita de dos caballeros enviados por Catilina para terminar con el Arpinata (Cat. I, 9-10). Plutarco nombra expresamente a Fulvia, basándose, pues, además de Cicerón en otras fuentes (Cic. 16, 1). Apiano se basa en Salustio, Floro en Livio y ambos nos dan el nombre y la acción realizada por Fulvia. También entre los conjurados de agosto hubo delatores y como prueba de esto, basta mencionar la manera como Cicerón llegó a penetrar en lo más íntimo del asunto de los alóbroges, en el cual tuvieron parte sobresaliente Umbreno y la matrona Sempronia, ambos conjurados del grupo de agosto; y después la frase, que llegó a ser común en la Catilinaria para indicar y enmascarar al mismo tiempo el espionaje: "ut comperi" (Cat. I, 10, 27). Salustio nos proporciona mayores detalles respecto al asunto de los alóbroges (Cat. $\mathrm{XL}$ ). Si se compara su narración con la de Cicerón parece que este último hablara con cierta reticencia, descuidando ciertos detalles que para nosotros adquieren suma importancia para determinar el 
comportamiento de algunos personajes. Salustio más claramente pone en relación a los alóbroges con los conjurados y nombra tanto a Umbreno como a Sempronia; sin embargo es prudente revisar la narración de Salustio con aquella que nos brinda Plutarco. Esta fuente es sin duda una de las más informadas sobre el periodo de la conjuración: Plutarco, en efecto, conoció un sin número de textos, entre los cuales los importantísimos comentarios de Tulio Tirón y llegó hasta a determinar el número de los embajadores alóbroges, cosa que ni Salustio ni Cicerón llegan a decirnos.

Plutarco nos habla, a propósito del asunto de los Alóbroges, acerca de un espionaje interno. ¿Quiénes serán los conjurados que se han prestado a este doble juego? Nosotros sabemos que Cicerón, por una comprensible reserva, no menciona jamás sus propios espías, ni durante la conjuración ni tampoco después. Por lo tanto, al confrontar el relato de Salustio con la III Catilinaria de Cicerón, podemos nosotros pensar, como posibles espías aquellas personas que Salustio menciona y Cicerón omite. Por esto, prescindiendo de los conjurados de junio, las únicas personas de las cuales se puede dudar son: Sempronia, Tito Volturcio y Quinto Fabio Sanga. De los tres, es menos probable éste último, puesto que la información de Salustio (XLI, 1), repetida a su vez por Apiano, no testimonia participación alguna de Quinto Fabio Sanga en la conjuración; aún más, casi ciertamente ésta no es una hipótesis de Salustio, pero sí de la fuente salustiana, la cual dio esta versión al acontecimiento. Los embajadores alóbroges se dirigen a su patrón, quien por su parte refiere la cosa a la autoridad consular, es decir a Cicerón. Pero esta versión oficial atestigua cierto desarrollo, que si bien sucedió, fue el último en cuanto a orden de tiempo; y fue posterior de otra información, la de cierto conjurado, como sabemos por testimonio de Plutarco. Ahora, entre los nombres que nos ha legado Salustio, sólo nos quedan los siguientes: Quinto Annio Quilón, Publio Furio, Umbreno, Tito Volturcio y Sempronia. Los tres primeros evidentemente no tuvieron ninguna relación con el cónsul; de hecho fueron fustigados por éste (Cat. III, $14 \mathrm{y}$ Cat. L, 4). De los otros dos, Volturcio sin duda a favor del cónsul, pero no es ciertamente el espía buscado por nosotros e indicado por Plutarco. Volturcio es personaje de segunda línea y también porque se había enrolado en las filas de los conjurados recientemente; sus tareas son limitadas. Se le encarga de acompañar los embajadores y de llevar cartas a Catilina. Cuando fue arrestado en el puen- te Milvio, sólo actúa por salvar el pellejo, con ventaja para el cónsul. No nos queda más que Sempronia. Además, que se trate de una espía mujer, puede barruntarse por un detalle del mismo texto de Plutarco ya citado (Cic. 18, 4).

Cicerón ni la nombra ni nos dice dónde aconteció la cita entre los conjurados y los embajadores alóbroges: este detalle de pie para corroborar la sospecha de que Sempronia sea la espía que, como de costumbre, Cicerón salva. Además de que se trata de una espía, se puede también deducir de una crítica interna al texto de Salustio. Ante todo la posición simétrica en el desarrollo lógico de la conjuración en las frases análogas: Sed in ea coniuratione... (XXIII, 1), comienza el capítulo sobre Fulvia y Curión; Sed in iis erat... (XXV, 1) así empieza el capítulo sobre Sempronia. Luego, que el valor del sed permanezca inalterado no obstante el abuso del cual suele hacer Salustio, podemos probarlo del hecho de que, no existiendo un concepto contrario en el periodo precedente, sino queriendo indicar una participación, emplea solamente: in iis erat, como por ejemplo en el caso de Fulvio (XXXIX, 5). Además, el hecho de haber Sempronia con frecuencia, traicionado antes de ese momento la palabra dada, no encontraría, como por lo demás todo el retrato, una explicación suficiente en sus precedentes desdichas financieras y tampoco en la breve frase: domus neque aliena propter Semproniam (XL, 5), si no se admitiese un hecho de aquella, de tal magnitud que pudiera superar los procedentes por maldad o al menos por no ser inferior a aquellos. Solamente así el retrato de Sempronia tiene razón de ser; y el odio de Salustio por esta persona se llega a entender claramente.

La sospecha que se cierne sobre esta persona, aumentada por la sombra protectora de Cicerón, provoca en Salustio una reacción, no obstante no serle posible una acusación abierta y no solamente el odio y la denigración sistemática del patriciado femenino, como la gran mayoría ha querido ver, concurre en esta figura, sino también la ira del partidario de César, que ve traicionada, por obra de una matrona, juguete en las manos de Cicerón, la obra hábil y escondidamente conducida, con la más refinada diplomacia, por la doble y concorde labor de César y Craso.

Si realmeñte, como parece, así se comportó Sempronia en la conjuración, se puede ver cuán falso sea el juicio, por muchos repetido, de que el retrato de Sempronia séa simétrico del de Catilina. 
Mejor se podría econtrar un cotejo fuera de la Catilinaria, en el retrato de Sila (Iug.XC), donde la similitud de las frases podría, en cierto sentido, aludir a la de los caracteres.

Para concluir, Sempronia permanece como de más interesantes personajes del retablo de la Conjuración de Catilina y su hechizo se acrecienta por el misterio que su no infundada sospecha de espionaje arroja sobre su personalidad y sobre su conducta.

\section{NOTAS}

(1) Bolaffi, Salustio e la sua fortuna nei secoli, Roma 1949, p. 133.
(2) Ciaceri, La dama Sempronia nella conguira de Catilina, in Atti della R. Accad, Napoli, 1930, p. 219 sgg.

\section{BIBLIOGRAFIA}

DELACROIX, Paul - Catilina, Salustio, Cayo Crispo. París, Libraire Hachette, 1969.

DIAZ Y DIAZ, Manuel -Conjuración de Catilina. Madrid, Credos s.f.

LA PE NNA, Antonio - Salustio e la rivoluzione romana. Milano, Feltrinelli, 1966
MILLARE S CARLO, Agustín. -Conjuración de Catilina. México, Universidad Autónoma, 1944.

STORONI MAZZOLANI, Lidia - La Congiura di Catilina. Milano, Biblioteca Universale Rizzoli, 1976.

ENCICLOPEDIA Italiana -1966. 